\title{
HIGH-RESOLUTION LIDAR DATA FOR PILGRIM HOT SPRINGS, WESTERN ALASKA, COLLECTED AUGUST 15, 2019
}

Andrew M. Herbst and Ronald J. Daanen

Raw Data File 2021-7

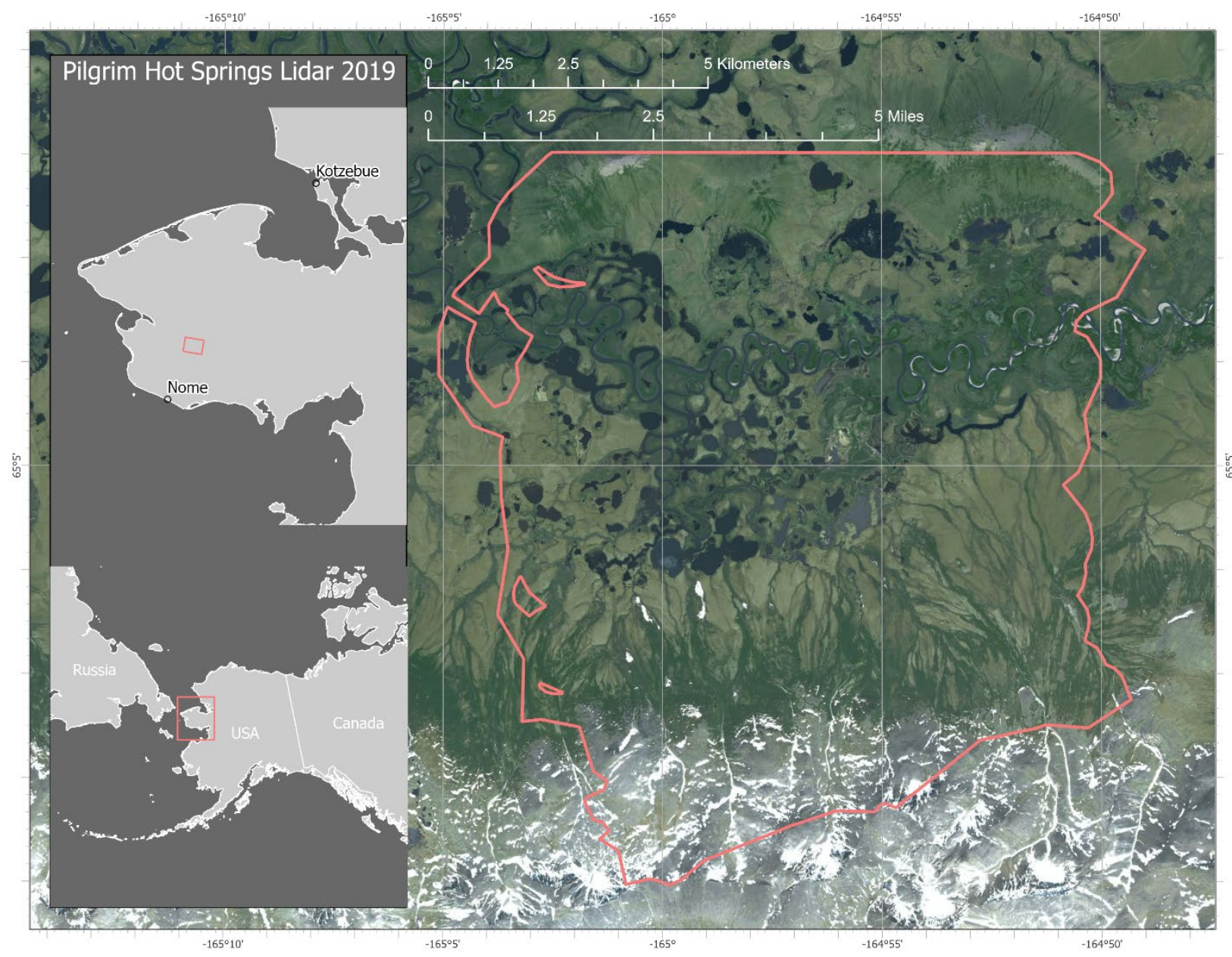

Location map of survey area with orthometric image.

This report has not been reviewed for technical content or for conformity to the editorial standards of DGGS.

2021

STATE OF ALASKA

DEPARTMENT OF NATURAL RESOURCES

DIVISION OF GEOLOGICAL \& GEOPHYSICAL SURVEYS

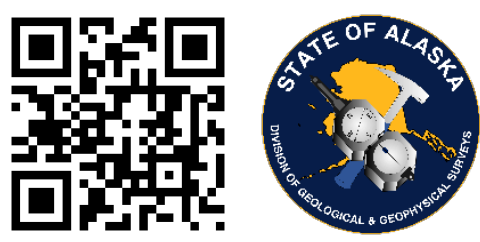


STATE OF ALASKA

Mike Dunleavy, Governor

DEPARTMENT OF NATURAL RESOURCES

Corri A. Feige, Commissioner

DIVISION OF GEOLOGICAL \& GEOPHYSICAL SURVEYS

Steve Masterman, State Geologist \& Director

Publications produced by the Division of Geological \& Geophysical Surveys are available to download from the DGGS website (dggs.alaska.gov). Publications on hard-copy or digital media can be examined or purchased in the Fairbanks office:

Alaska Division of Geological \& Geophysical Surveys (DGGS)

3354 College Road | Fairbanks, Alaska 99709-3707

Phone: 907.451.5010 | Fax 907.451.5050

dggspubs@alaska.gov | dggs.alaska.gov

DGGS publications are also available at:

Alaska State Library, Historical

Collections \& Talking Book Center

395 Whittier Street

Juneau, Alaska 99801

Alaska Resource Library and

Information Services (ARLIS)

3150 C Street, Suite 100

Anchorage, Alaska 99503

\section{Suggested citation:}

Herbst, A.M., and Daanen, R.P., 2021, High-Resolution lidar data for Pilgrim Hot Springs, western Alaska, collected August 15, 2019:

Alaska Division of Geological \& Geophysical Surveys Raw Data File 2021-7, 6 p. http://doi.org/10.14509/30659
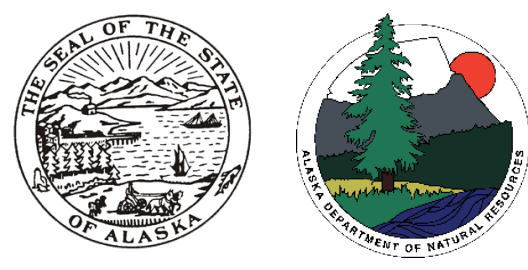


\section{HIGH-RESOLUTION LIDAR DATA FOR PILGRIM HOT SPRINGS, WESTERN ALASKA, COLLECTED AUGUST 15, 2019}

Andrew M. Herbst ${ }^{1}$ and Ronald P. Daanen ${ }^{1}$

\section{ABSTRACT}

The State of Alaska Division of Geological \& Geophysical Surveys (DGGS) produced airborne lidar-derived elevation data for the Pilgrim Hot Springs area, western Alaska. Both aerial lidar and ground control data were collected by DGGS. This data collection is being released as a Raw Data File with an open end-user license. These data were produced in support of active fault detection and geothermal hydrology research in the area. All files can be downloaded from the DGGS website at https://doi.org/10.14509/30659.

\section{INTRODUCTION}

\section{LIST OF DELIVERABLES}

Classified Points

DSM and DTM

Intensity Image

Metadata

\section{MISSION PLAN}

\section{Airborne Survey Details}

This dataset includes point cloud data, a digital terrain model (DTM), and a digital surface model (DSM) covering Pilgrim Hot Springs, western Alaska (approximately $47 \mathrm{mi}^{2}$ ). This survey was conducted with a DGGS-operated Riegl VUX1-LR lidar system with an integrated Global Navigation Satellite System (GNSS) receiver and Northrop Grumman inertial measurement unit (IMU) system. The integration was designed by Phoenix LiDAR systems. This survey was flown with a pulse rate between 200,000 and 400,000 pulses/second, at a scan rate between 80 and 150 scans/second. This survey was flown with an average elevation of $400 \mathrm{~m}$ above ground level and a ground speed of approximately $40 \mathrm{~m} / \mathrm{s}$ with a fixed-wing aircraft configuration, using a Cessna 185 aircraft (fig. 1). The scan angle was set from 55 to 305 degrees, centered normal to the bottom of the aircraft.

\section{Weather Conditions and Flight Times}

The airborne survey occurred on August 15, 2019, with ground control collected on August 14,2019 . The weather was clear throughout the survey.

\footnotetext{
${ }^{1}$ Alaska Division of Geological \& Geophysical Surveys, 3354 College Road, Fairbanks, Alaska 99709
} 


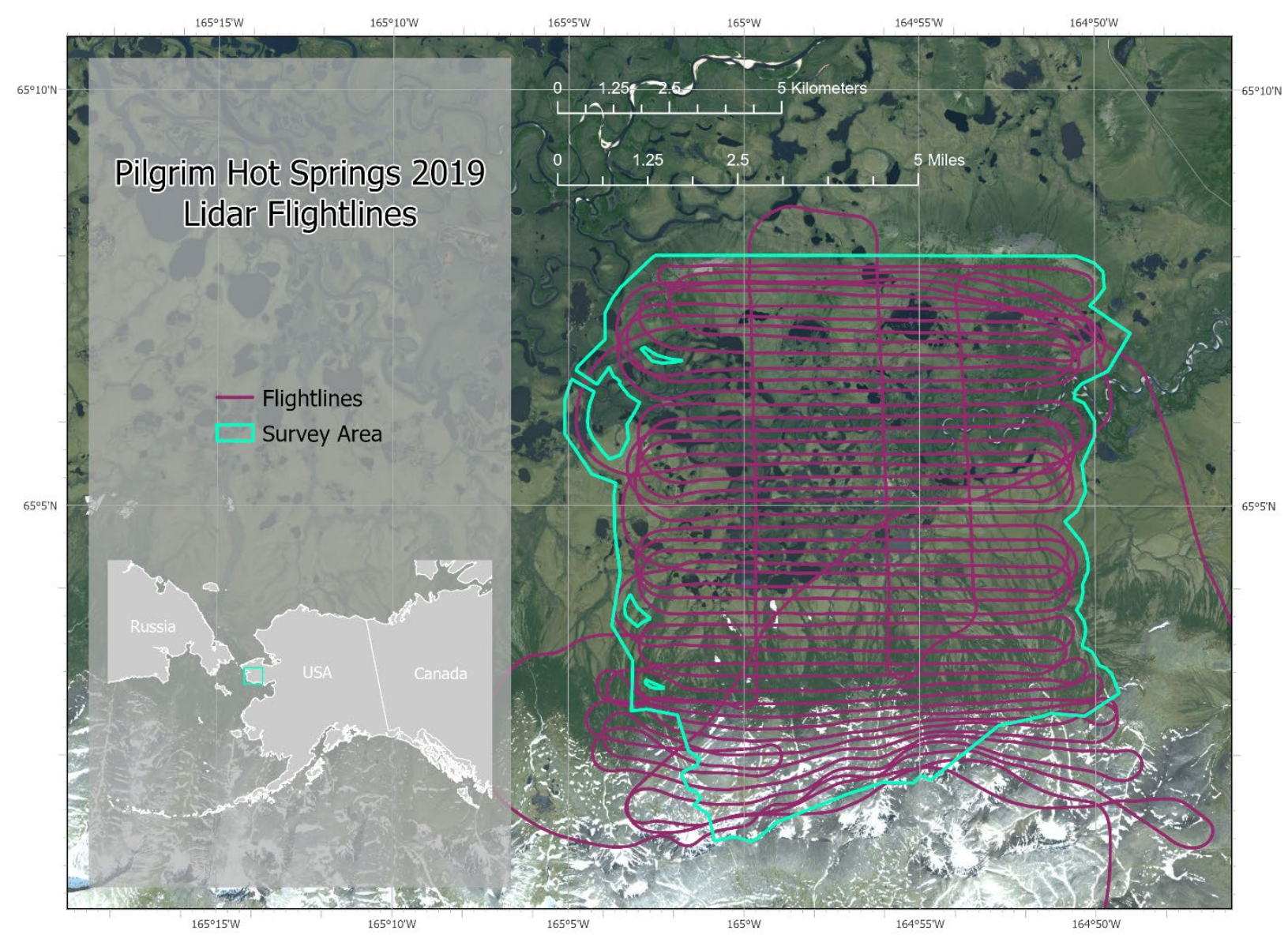

Figure 1. Project flightlines.

\section{PROCESSING REPORT}

\section{Lidar Dataset Processing}

Point data were processed in SDCimport software for initial filtering and multiple-timearound (MTA) disambiguation. MTA errors, corrected in this process, are the result of imprecise interpretations of received pulse time intervals and occur more frequently with higher pulse refresh rates. IMU and GPS data were used to integrate flightline information with the point cloud in Spatial Explorer software. The point data were calibrated at an incrementally precise scale of sensor movement and behavior, incorporating sensor velocity, roll, pitch, and yaw fluctuations throughout the survey.

Points were classified in accordance with the American Society for Photogrammetry and Remote Sensing (ASPRS) 2014 guidelines, using macros designed in Terrasolid software. Careful attention was given to the interpolation of the project's ground surface to compensate for inconsistent penetration through low vegetation as a function of the scan angle. Once classified, 
points underwent a geometric transformation and were converted from ellipsoidal heights to GEOID12B (Alaska) heights.

Raster products were derived from the point cloud using ArcMap. The DTM was interpolated from all ground class returns using a mean binning method. The DSM was likewise interpolated from only the first returns for all classes. An intensity image was produced in ArcMap using mean binning.

\section{Classified Point Cloud}

Classified point cloud data are provided in this collection in compressed LAZ format. Data are classified in accordance with ASPRS 2014 guidelines and contain return and intensity information. The average point spacing was $27 \mathrm{~cm}$ and the average density was $13.92 \mathrm{pts} / \mathrm{m}^{2}$ (fig. 2). Elevation surfaces interpolated from areas with a point density of fewer than $4 \mathrm{pts} / \mathrm{m}^{2}$ were classified as NoData.

\section{Digital Surface Model}

The DSM represents surface elevations, including heights of vegetation, buildings, bridges, etc. The DSM is a single band, 32-bit GeoTIFF file, with a ground sample distance of 1 meter. NoData value is set to $-3.40282306074 \mathrm{e}+038$.

\section{Digital Terrain Model}

The DTM represents surface elevations of ground surfaces, excluding vegetation, bridges, buildings, etc. The DTM is a single-band, 32-bit float GeoTIFF file, with a ground sample distance of 1 meters. NoData value is set to $-3.40282306074 \mathrm{e}+038$.

\section{Lidar Intensity Image}

The lidar intensity image describes the relative amplitude of reflected signals contributing to the point cloud. Lidar intensity is largely a function of scanned object reflectance in relation to the signal frequency, is dependent on ambient conditions, and is not necessarily consistent between separate scans. The intensity image is a single-band, 32-bit float GeoTIFF file with a ground sample distance of 1 meter. NoData value is set to -3.40282306074e+038 (32-bit, floatingpoint minimum).

\section{SURVEY REPORT}

\section{Ground Survey Details}

Trimble R8 and R9 real-time kinematic GNSS systems were used to collect 62 combined checkpoints and control points for the project. Points were adjusted for accuracy according to Online Positioning User Service (OPUS) corrections in Trimble Business Center.

\section{Coordinate system and Datum}

All data were processed and delivered in NAD83 (2011) UTM3N and vertical datum NAVD88, GEOID12B. 


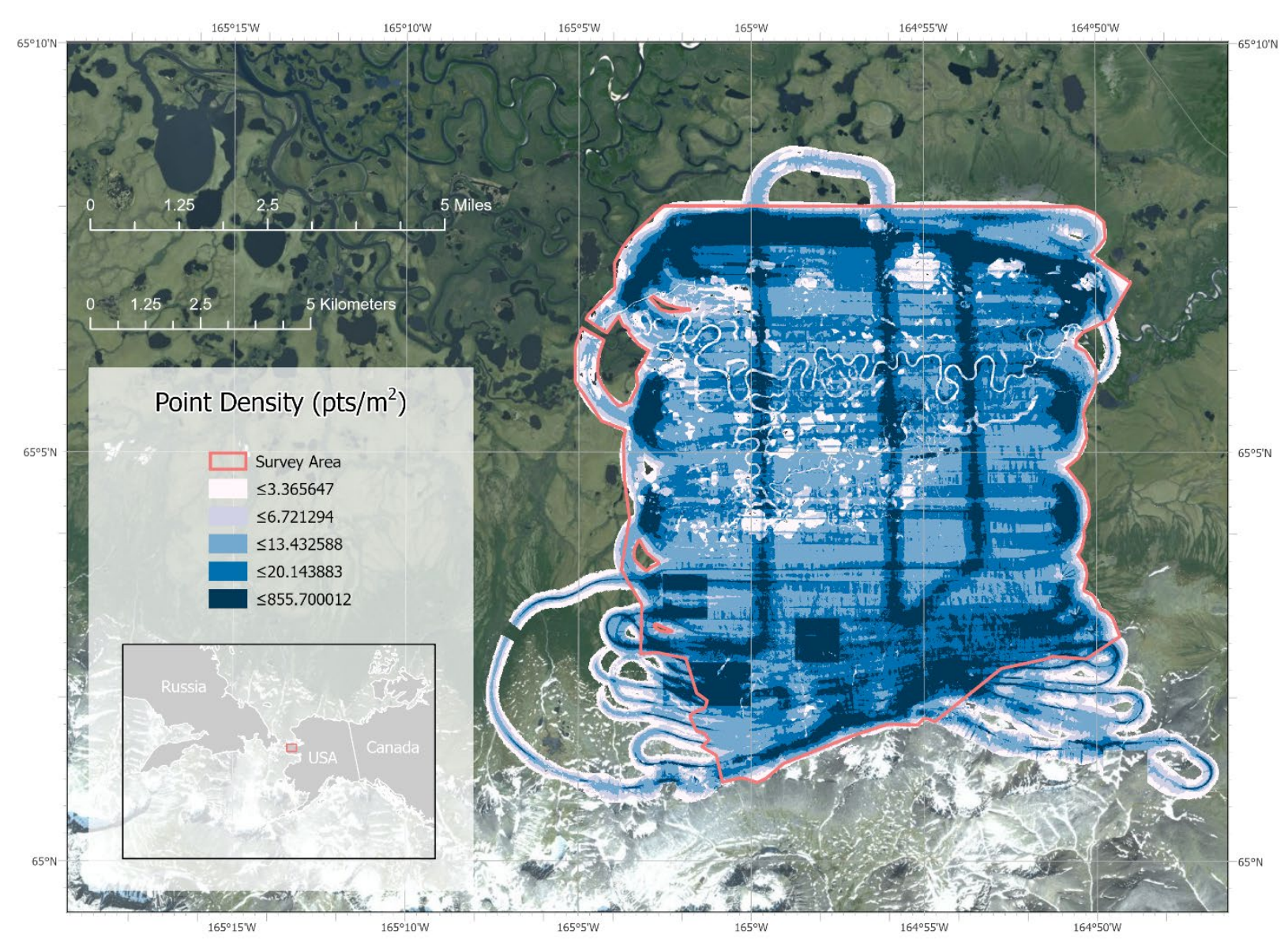

Figure 2. Ground point density for the survey displayed as a 1-meter raster.

\section{Horizontal Accuracy}

Horizontal accuracy was not measured for this collection.

\section{Vertical Accuracy}

Thirty-one ground control points were used to determine a $0.11 \mathrm{~m}$ average offset from the point cloud (app. 1), which was corrected with a uniform z-transformation of the lidar data. Point cloud accuracy was measured using 31 checkpoints to determine a root-mean-square error of 0.087 $\mathrm{m}$ for the project (app. 2). Relative accuracy for this dataset has been evaluated as the interswath consistency, measured by comparing tie line points within swath overlap areas. The interswath root-mean-square error was calculated to be 0.008 meters.

\section{Data Consistency and Completeness}

This data release is complete, and there is no over collect, except for the aircraft turns that were eliminated from the dataset. The data quality is consistent throughout the survey.

\section{ACKNOWLEDGMENTS}

These data were paid for by the State of Alaska and collected and processed by DGGS. 
APPENDIX 1. CONTROL POINTS

\begin{tabular}{|c|c|c|c|c|c|}
\hline Number & Easting (m) & Northing (m) & $\begin{array}{c}\text { Known Z } \\
(\mathrm{m})\end{array}$ & $\begin{array}{c}\text { Laser Z } \\
(\mathrm{m}) \\
\end{array}$ & $\begin{array}{l}\mathrm{Dz} \\
(\mathrm{m}) \\
\end{array}$ \\
\hline 1 & 503703.878 & 7218097.483 & 4.973 & 5.040 & 0.067 \\
\hline 2 & 503649.164 & 7218143.976 & 5.258 & 5.310 & 0.052 \\
\hline 3 & 503625.573 & 7218188.073 & 4.925 & 4.980 & 0.055 \\
\hline 4 & 503573.001 & 7218600.977 & 4.952 & 4.990 & 0.038 \\
\hline 5 & 503560.189 & 7218666.124 & 4.812 & 4.920 & 0.108 \\
\hline 6 & 503540.102 & 7218718.466 & 5.258 & 5.290 & 0.032 \\
\hline 7 & 503563.601 & 7218768.335 & 5.574 & 5.740 & 0.166 \\
\hline 8 & 503658.812 & 7218804.373 & 5.025 & 5.150 & 0.125 \\
\hline 9 & 503719.533 & 7218824.089 & 5.149 & 5.270 & 0.121 \\
\hline 10 & 503761.246 & 7218833.978 & 4.883 & 4.940 & 0.057 \\
\hline 11 & 503861.460 & 7218909.163 & 4.920 & 4.960 & 0.040 \\
\hline 12 & 503957.781 & 7218996.531 & 4.857 & 4.990 & 0.133 \\
\hline 13 & 504042.793 & 7219059.576 & 4.914 & 5.040 & 0.126 \\
\hline 14 & 504109.987 & 7219072.728 & 5.327 & 5.470 & 0.143 \\
\hline 15 & 504157.601 & 7219089.806 & 5.502 & 5.550 & 0.048 \\
\hline 16 & 504180.730 & 7219119.014 & 4.123 & 4.180 & 0.057 \\
\hline 17 & 503545.945 & 7218861.500 & 5.312 & 5.420 & 0.108 \\
\hline 18 & 503478.666 & 7219009.436 & 4.601 & 4.740 & 0.139 \\
\hline 19 & 503415.808 & 7219056.588 & 4.817 & 5.070 & 0.253 \\
\hline 20 & 503361.058 & 7219116.104 & 4.939 & 5.240 & 0.301 \\
\hline 21 & 503297.875 & 7219141.310 & 4.571 & 4.930 & 0.359 \\
\hline 22 & 503413.996 & 7218598.676 & 5.700 & 5.760 & 0.060 \\
\hline 23 & 503397.047 & 7218550.073 & 5.216 & 5.280 & 0.064 \\
\hline 24 & 503401.099 & 7218530.192 & 5.209 & 5.290 & 0.081 \\
\hline 25 & 503387.213 & 7218488.279 & 5.223 & 5.320 & 0.097 \\
\hline 26 & 503362.208 & 7218428.584 & 4.720 & 4.910 & 0.190 \\
\hline 27 & 503284.009 & 7218459.250 & 4.646 & 4.770 & 0.124 \\
\hline 28 & 503254.094 & 7218470.398 & 4.682 & 4.760 & 0.078 \\
\hline 29 & 503229.915 & 7218482.195 & 4.605 & 4.670 & 0.065 \\
\hline 30 & 503126.062 & 7218456.030 & 4.332 & 4.440 & 0.108 \\
\hline 31 & 503110.431 & 7218455.493 & 4.255 & 4.330 & 0.075 \\
\hline
\end{tabular}

\begin{tabular}{|l||l|}
\hline Average dz $(\mathrm{m})$ & 0.112 \\
\hline \hline Minimum dz $(\mathrm{m})$ & 0.032 \\
\hline \hline Maximum dz $(\mathrm{m})$ & 0.359 \\
\hline \hline Average magnitude $(\mathrm{m})$ & 0.112 \\
\hline \hline Root mean square $(\mathrm{m})$ & 0.135 \\
\hline \hline Standard deviation $(\mathrm{m})$ & 0.076 \\
\hline
\end{tabular}


APPENDIX 2. CHECKPOINTS

\begin{tabular}{|c|c|c|c|c|c|}
\hline Number & Easting $(\mathrm{m})$ & Northing (m) & Known Z (m) & Laser Z (m) & $\mathrm{Dz}(\mathrm{m})$ \\
\hline 1 & 503681.026 & 7218116.757 & 5.062 & 5.020 & -0.042 \\
\hline 2 & 503630.105 & 7218161.748 & 5.083 & 5.020 & -0.063 \\
\hline 3 & 503574.179 & 7218578.425 & 5.093 & 5.050 & -0.043 \\
\hline 4 & 503571.315 & 7218636.820 & 4.734 & 4.690 & -0.044 \\
\hline 5 & 503552.094 & 7218678.700 & 4.750 & 4.690 & -0.060 \\
\hline 6 & 503551.343 & 7218748.208 & 5.475 & 5.500 & 0.025 \\
\hline 7 & 503584.602 & 7218780.386 & 4.805 & 4.760 & -0.045 \\
\hline 8 & 503692.638 & 7218818.247 & 4.856 & 4.800 & -0.056 \\
\hline 9 & 503744.280 & 7218830.310 & 5.026 & 5.110 & 0.084 \\
\hline 10 & 503786.750 & 7218846.373 & 5.055 & 4.960 & -0.095 \\
\hline 11 & 503906.306 & 7218951.968 & 4.752 & 4.740 & -0.012 \\
\hline 12 & 504007.614 & 7219034.216 & 5.104 & 5.230 & 0.126 \\
\hline 13 & 504071.599 & 7219079.588 & 5.177 & 5.120 & -0.057 \\
\hline 14 & 504119.277 & 7219097.393 & 5.403 & 5.370 & -0.033 \\
\hline 15 & 504176.789 & 7219094.489 & 4.998 & 4.960 & -0.038 \\
\hline 16 & 503542.897 & 7218852.777 & 5.322 & 5.380 & 0.058 \\
\hline 17 & 503508.226 & 7218871.342 & 4.758 & 4.750 & -0.008 \\
\hline 18 & 503479.100 & 7219047.097 & 4.823 & 4.670 & -0.153 \\
\hline 19 & 503372.827 & 7219102.661 & 4.634 & 4.880 & 0.246 \\
\hline 20 & 503312.129 & 7219132.910 & 4.650 & 4.870 & 0.220 \\
\hline 21 & 503419.213 & 7218605.933 & 5.542 & 5.520 & -0.022 \\
\hline 22 & 503421.781 & 7218590.445 & 5.976 & 5.940 & -0.036 \\
\hline 23 & 503409.900 & 7218539.350 & 5.627 & 5.610 & -0.017 \\
\hline 24 & 503398.798 & 7218518.426 & 5.169 & 5.140 & -0.029 \\
\hline 25 & 503381.035 & 7218451.175 & 5.226 & 5.200 & -0.026 \\
\hline 26 & 503355.837 & 7218433.090 & 4.878 & 4.990 & 0.112 \\
\hline 27 & 503264.828 & 7218464.975 & 4.756 & 4.710 & -0.046 \\
\hline 28 & 503232.307 & 7218477.119 & 4.622 & 4.560 & -0.062 \\
\hline 29 & 503147.751 & 7218461.717 & 4.396 & 4.440 & 0.044 \\
\hline 30 & 503122.653 & 7218492.332 & 3.555 & 3.470 & -0.085 \\
\hline 31 & 503107.109 & 7218399.449 & 4.696 & 4.580 & -0.116 \\
\hline
\end{tabular}

\begin{tabular}{||l|r|}
\hline Average dz $(\mathrm{m})$ & -0.009 \\
\hline \hline Minimum dz $(\mathrm{m})$ & -0.153 \\
\hline \hline Maximum dz $(\mathrm{m})$ & 0.246 \\
\hline \hline Average magnitude $(\mathrm{m})$ & $\mathbf{0 . 0 6 8}$ \\
\hline \hline Root mean square $(\mathrm{m})$ & $\mathbf{0 . 0 8 7}$ \\
\hline \hline Standard deviation $(\mathrm{m})$ & $\mathbf{0 . 0 8 8}$ \\
\hline
\end{tabular}

